\title{
Starch from the Sago (Metroxylon sagu) palm tree - properties, prospects, and challenges as a new industrial source for food and other uses
}

\begin{abstract}
The common industrial starches are typically derived from cereals (corn, wheat, rice, sorghum), tubers (potato, sweet potato), roots (cassava), and legumes (mung bean, green pea). Sago (Metroxylon sagu Rottb.) starch is perhaps the only example of commercial starch derived from another source, the stem of palm (sago palm). Sago palm has the ability to thrive in the harsh swampy peat environment of certain areas. It is estimated that there are about 2 million ha of natural sago palm forests and about 0.14 million ha of planted sago palm at present, out of a total swamp area of about 20 million ha in Asia and the Pacific Region, most of which are under- or nonutilized. Growing in a suitable environment with organized farming practices, sago palm could have a yield potential of up to 25 tons of starch per hectare per year. Sago starch yield per unit area could be about 3 to 4 times higher than that of rice, corn, or wheat, and about 17 times higher than that of cassava. Compared to the common industrial starches, however, sago starch has been somewhat neglected and relatively less attention has been devoted to the sago palm and its starch. Nevertheless, a number of studies have been published covering various aspects of sago starch such as molecular structure, physicochemical and functional properties, chemical/physical modifications, and quality issues. This article is intended to piece together the accumulated knowledge and highlight some pertinent information related to sago palm and sago starch studies.
\end{abstract}

Keyword: Sago palm tree; Starch; New industrial source; Food; Uses. 